\title{
Effect of Lactobacillus plantarum FH185 on the Reduction of Adipocyte Size and Gut Microbial Changes in Mice with Diet-induced Obesity
}

\author{
Sun-Young Park, Seong-A Cho, Myung-Ki Lee, and Sang-Dong Lim* \\ Korea Food Research Institute, Seongnam 463-746, Korea
}

\begin{abstract}
This study aimed to investigate the effects of Lactobacillus plantarum FH185 on the reduction of adipocyte size and gut microbial changes in mice with diet-induced obesity. The strain was found to have a lipase inhibitory activity of $70.09 \pm 2.04 \%$ and inhibited adipocyte differentiation of 3T3-L1 cells $(18.63 \pm 0.98 \%)$ at a concentration of $100 \mu \mathrm{g} / \mathrm{mL}$. To examine the effect of the strain supplementation on gut microbial changes in mice with diet-induced obesity, male C57BL/6J mice were fed on four different diets (i.e., A, normal diet (ND); B, high-fat diet (HFD); C, HFD with ABT-3 ( $10^{9}$ CFU/day); and D, HFD with L. plantarum FH185 (109 CFU/day)) for 6 wk. According to the results of fecal pyrosequencing, the ratio of Firmicutes to Bacteroidetes in groups $\mathrm{C}$ and $\mathrm{D}$ was lower than in the control groups at the phylum level. At the family level, Lactobacillaceae in groups C and D was observed to dominate, while Lachnospiraceae in groups A and B was observed to dominate. At the genus level, Lactobacillus in groups $\mathrm{C}$ and D was comparatively higher than in groups $\mathrm{A}$ and B. To examine the effects of strain supplementation on the reduction of adipocyte size, the left and right epididymal fat pads were quickly isolated after the animals were sacrificed, and the adipocyte sizes were measured. In groups A, C and D, the percentage of 2,000 $\mathrm{m}^{2}$ of adipocyte was higher than in the other size of adipocyte, while the percentage of over 5,000 $\mathrm{m}^{2}$ of adipocyte was highest in group B. The mean adipocyte size of group D was significantly larger than that of group A, but smaller than that of group B.
\end{abstract}

Key words: Lactobacillus plantarum, anti-lipase activity, anti-adipogenetic activity, gut microbiota, adipocyte size

Received October 24, 2014 / Revised January 12, 2015 / Accepted January 13, 2015

\section{Introduction}

Obesity, a condition in which an abnormally large amount of fat is stored in the body's adipose tissue, resulting in an increase in body weight, is one of a number of critical pandemics and health problems that it is rapidly becoming a worldwide epidemic (An et al., 2011). Obesity has been linked to a variety of chronic diseases such as comorbidities of cardiovascular diseases (CVD), type-2 diabetes, certain cancers, and sleep apnea/sleepdisordered breathing, and is thought to be responsible for almost 300,000 deaths each year (Haslam and James, 2005; Stein and Colditz, 2004). It is generally known that a high-fat diet (HFD) is one of various factors that cause obesity, and that the long-term intake of such a diet induces a significant increase in abdominal fat weight. Therefore, many food science researchers have concentrated on finding a food or beverage with a function that prevents HFD-induced obesity (Iwashita et al., 2002; Tanida et al.,

\footnotetext{
*Corresponding author: Sang-Dong Lim, Korea Food Research Institute, Seongnam 463-746, Korea. Tel: +82-31-780-9082, Fax: +82-31-780-9160, E-mail: limsd@kfri.re.kr
}

2008).

Recently, there has been an increase in studies of the differences in the composition of gut microbiota between obese and lean individuals, and these have demonstrated that obesity is associated with an imbalance in the normal gut microbiota (Arora et al., 2012; Turnbaugh et al., 2009). In healthy adults, $80 \%$ of the identified fecal microbiota can be classified into three dominant phyla: Bacteroidetes, Firmicutes and Actinobacteril (Lay et al. 2005). In general, the Firmicutes to Bacteroidetes ratio is thought to be particularly relevant to the composition of human microbiota. The ratio differs in obese and lean humans, and this proportion decreases with weight loss on a low-calorie diet (Ley et al. 2006).

Probiotics, consisting of individual or multiple live bacteria species such as Lactobacillus and bifidobacteria, confer a health benefit on the host when administered in adequate amounts. Probiotics directly alter the gut microbiota (Delzenne et al., 2011; FAO and WHO, 2001). Several studies have reported the health-promoting effects of probiotics, including the maintenance of intestinal mucosal resistance to pathogenic microorganisms (Mennigen and Bruewer, 2009), the prevention of diarrhea (Guanda- 
lini, 2008), immunomodulation (Perdigón et al., 2001), reduced serum cholesterol levels (Nguyen et al., 2007), and the prevention of certain allergies and cancers (Isolauri and Salminen, 2008; Kumar et al., 2010). Other studies also demonstrate that some probiotic can be used to control bodyweight and metabolic disorders (Bhathena et al., 2009; Lee et al., 2007).

The aim of this study was to investigate the effect of $L$. plantarum FH185 on the reduction of adipocyte size and gut microbial changes in mice with diet-induced obesity.

\section{Materials and Methods}

\section{Isolation of lactic acid bacteria}

The strain FH185 was isolated from the feces of healthy adults in a modified MRS medium (Lim et al., 2011), and incubated in lactobacilli MRS broth (Difco, USA) as the growth medium at $37^{\circ} \mathrm{C}$ for $18 \mathrm{~h}$.

\section{Identification of FH185 strain}

The properties of the FH185 strain were investigated by testing with Gram staining and microscopic observation after cultivation in an MRS broth for $18 \mathrm{~h}$ at $37^{\circ} \mathrm{C}$. Bergey's Manual of Systematic Bacteriology by Rogosa (1974) was used to examine the morphological and physiological properties of the isolated strains. The FH185 strain was identified using the $16 \mathrm{~S}$ rDNA sequencing method. The chromosomal DNA of the isolated strain was separated using a SolGent Genomic DNA prep kit (SolGent, Korea). The DNA extracts were used for the polymerase chain reaction (PCR) with universal primers [27F (5'-AGA GTT TGA TCC TGG CTC AG-3') and 1492R (5'-GGT TAC CTT GTT ACG ACT T-3')]. PCR was carried out in a programmable therma cycler (SolGent EF-Taq, Korea), according to the following steps: one cycle of denaturation at $95^{\circ} \mathrm{C}$ for $15 \mathrm{~min}$, followed by 30 cycles of $95^{\circ} \mathrm{C}$ for $20 \mathrm{~s}, 50^{\circ} \mathrm{C}$ for $40 \mathrm{~s}$, and $72^{\circ} \mathrm{C}$ for $90 \mathrm{~s}$. The final extension was carried out at $72^{\circ} \mathrm{C}$ for $5 \mathrm{~min}$. The purified PCR product obtained using a SolGent PCR purification kit (SolGent) was used for sequencing with an ABI 3730XL DNA analyzer (Applied Biosystems, USA).

\section{Anti-lipase activity}

A modified version of a method of lipase activity determination (by Lee et al., 1993) was used. The pancreatic lipase activity was measured using porcine pancreatic lipase (Sigma chemical, USA). $0.1 \mathrm{mg} / \mathrm{mL}$ of a sample solution dissolved in water, and $0.167 \mathrm{mM} p$-Nitrophenylpalmitate (PNP; Sigma) solution and 0.061 M (pH 8.5) Tris-
HCL buffer were mixed in the well of a plate, to which $0.3 \mathrm{mg} / \mathrm{mL}$ of the lipase solution was then added to start the enzyme reaction. After incubation at $25^{\circ} \mathrm{C}$ for $10 \mathrm{~min}$, its absorbance was measured at $405 \mathrm{~nm}$.

\section{Anti-adipogenetic activity}

\section{Cell line and cell culture}

3T3-L1 cells were obtained from the American Type Culture Collection (ATCC, USA) and cultured at $37^{\circ} \mathrm{C}$ in a humidified 5\% $\mathrm{CO}_{2}$ atmosphere. 3T3-L1 cells were cultured as described by Hemati et al. (1997). Briefly, the cells were grown in Dulbecco's modified Eagle's medium (DMEM; GIBCO Lab., USA) containing high glucose content, supplemented with $10 \%$ bovine calf serum (BCS; GIBCO) and 1\% penicillin/streptomycin in six well culture plates. Two days later, confluence cells were cultured in an adipocyte differentiation cocktail medium containing 0.5 mM 3-isobutyl-1-methylxanthine (IBMX; Sigma), $1 \mathrm{M}$ dexamethasone (Dex; Sigma), and $5 \mathrm{~g} / \mathrm{mL}$ insulin (Sigma) in DMEM supplemented with $10 \%$ fetal bovine serum (FBS; GIBCO) for $2 \mathrm{~d}$. The differentiation was complete after $6 \mathrm{~d}$.

\section{Sample preparation and treatment of $L$. plantarum} $\mathrm{FH} 185$

L. plantarum $\mathrm{FH} 185$ was incubated at $37^{\circ} \mathrm{C}$ for $18 \mathrm{~h}$ in MRS broth. All of the purified strains were kept at $-70^{\circ} \mathrm{C}$ until use. After culturing L. plantarum $\mathrm{FH} 185$, all of the strains were harvested in a refrigerated centrifuge $(1,500 \mathrm{~g}$ for $15 \mathrm{~min}$ at $4^{\circ} \mathrm{C}$ ) and washed three times with distilled water to remove any remaining MRS broth. The washed L. plantarum FH185 was freeze-dried and re-suspended in distilled water at a concentration of $10 \mathrm{mg} / \mathrm{mL}$, and then homogenized for $50 \mathrm{~s}$ followed by $1 \mathrm{~min}$ of rest (repeated 3 times) using a sonicator. The 3T3-L1 cells were treated with three different concentrations of supernatant, i.e., $0 \mathrm{~g} / \mathrm{mL}$ (control), $10 \mathrm{~g} / \mathrm{mL}$ and $100 \mathrm{~g} / \mathrm{mL}$.

\section{Oil red $\mathrm{O}$ staining of 3T3-L1 adipocytes}

Intracellular lipid accumulation was measured using oil red O (Sigma). Oil red O straining of 3T3-L1 cells was performed using a modified version of the method described by Ramirez-Zacarias et al. (1992). 3T3-L1 cells were washed with PBS twice, fixed with $10 \%$ formaldehyde/ PBS at $4^{\circ} \mathrm{C}$ for $1 \mathrm{~h}$, and stained with filtered oil red $\mathrm{O}$ solution (stock solution: $3.5 \mathrm{mg} / \mathrm{mL}$ in isopropanol; working solution: $60 \%$ oil red $\mathrm{O}$ stock solution and $40 \%$ distilled water) at room temperature for $30 \mathrm{~min}$. The quanti- 
fication of lipid accumulation was achieved by oil red $\mathrm{O}$ obtained from stained cells with isopropyl alcohol and measured spectrophotometrically at $520 \mathrm{~nm}$. The material stained with oil red $\mathrm{O}$ was expressed on a per cell basis using the cell number determined from similar plates. The percentage of the material stained with oil red $\mathrm{O}$ relative to the control wells containing the cell culture medium without compounds was calculated as $520 \mathrm{~nm}$ (FH185)/ $520 \mathrm{~nm}$ (control) $\times 100$.

\section{Change of gut microbiota and adipocyte size}

\section{Animals and treatments}

Male C57BL/6J mice aged $6 \mathrm{wk}$ were purchased from DooYeol Biotech (Korea). All of the mice were individually housed at a constant temperature and humidity (20 \pm $2^{\circ} \mathrm{C}, 55 \pm 10 \%$ ) under a $12 \mathrm{~h}$ light/dark cycle. After acclimatization for $1 \mathrm{wk}$ on a normal chow diet, they were then randomized according to their body weights and divided into four groups of 6 mice. The mice were fed either a high-fat diet (HFD; $n=18$ ) or a normal diet (ND; $n=6$ ) for $6 \mathrm{wk}$. In calorific terms, the high-fat diet consisted of $34.3 \%$ fat, $27.3 \%$ carbohydrate, and $34.3 \%$ protein $(5.1$ $\mathrm{kcal} / \mathrm{g}$ ), whereas the normal diet contained $4.2 \%$ fat, $64.7 \%$ carbohydrate, and $18.6 \%$ protein $(3.7 \mathrm{kcal} / \mathrm{g})$. The compositions of HFD and ND are given in Table 1. The groups of mice were fed as follows: Group A was fed a normal diet and orally administrated with saline solution; Group $\mathrm{B}$ was fed a high-fat diet and orally administrated with saline solution; Group C was fed a high-fat diet and orally administrated with ABT-3 (at $10^{9} \mathrm{CFU} /$ day), a commercial probiotic start culture obtained from Chr. Hansen's Laboratory (Denmark), in saline solution; and Group D was fed a high-fat diet and orally administrated with $L$.

Table 1. The formula of normal diet and high fat diet

\begin{tabular}{ccc}
\hline \hline & \multicolumn{2}{c}{$\mathrm{g} / \mathrm{kg}$} \\
\cline { 2 - 3 } Formula & $\begin{array}{c}\text { Normal diet High fat diet } \\
(\mathrm{ND})\end{array}$ & $(\mathrm{HFD})$ \\
\hline Casein & 210.0 & 265.0 \\
L-Cystine & 3.0 & 4.0 \\
Maltodextrin & 50.0 & 160.0 \\
Sucrose & 325.0 & 90.0 \\
Lard & 20.0 & 310.0 \\
Soybean Oil & 20.0 & 30.0 \\
Cellulose & 37.15 & 65.5 \\
Mineral Mix, AIN-93G-MX(94046) & 35.0 & 48.0 \\
Calcium Phosphate, dibasic & 2.0 & 3.4 \\
Vitamin Mix, AIN-93-VX(94047) & 15.0 & 21.0 \\
Choline Bitartrate & 2.75 & 3.0 \\
Food Color & 0.1 & 0.1 \\
\hline
\end{tabular}

plantarum FH185 (109 CFU/day) in saline solution. Food and water were freely available, and ABT-3 and L. plantarum FH185 in saline solution, or only saline solution, were orally administered once a day for $6 \mathrm{wk}(2.5 \mathrm{~g} / \mathrm{g}$ body weight). Probiotics were suspended in sterilized saline solution immediately before being orally administered to the mice. Before being sacrificed, the mice were fasted for $12 \mathrm{~h}$ and anesthetized with diethyl ether. All animal experimentation was performed after obtaining the approval of the Institutional Animal Care and Use Committee (IACUC) of Seoul National University College of Medicine.

Bacterial 16S rRNA gene amplification and barcoded pyrosequencing

Fecal samples were collected on the first day of $0 \mathrm{wk}$ and on the last day of $6 \mathrm{wk}$ to analyze the fecal microbiota, and the samples were stored at $-80^{\circ} \mathrm{C}$ prior to DNA extraction. For analysis of the microbial content, the genomic DNA was extracted from the fecal samples of all the mice using a G-spin ${ }^{\mathrm{TM}}$ Genomic DNA Extraction Kit (iNtRON Biotechnology, Seoul, Korea) according to the manufacturer's instructions. The extracted DNA was amplified using primers targeting the V1 to V3 hypervariable regions of the bacterial 16S rRNA gene (V1-9F: 5'-X-AC-GAGTTTGATCMTGGCTCAG-3' and V3-541R: 5'-X-AC-WTTACCGCGGCTGCTGG-3', where X denotes the uniquely designed barcode for each mouse followed by a common linker AC). In this study, mixtures of barcodes of varying lengths (7 to 11 base pairs) were used. To amplify the $16 \mathrm{~S}$ rRNA genes, the polymerase chain reaction (PCR) was performed with the universal primers 8F and 338R (Liu et al., 1997). The PCR consisted of a $95^{\circ} \mathrm{C}$ hold for $120 \mathrm{~s}$, followed by 35 cycles of $1 \mathrm{~min}$ at $95^{\circ} \mathrm{C}, 30 \mathrm{~s}$ at $58^{\circ} \mathrm{C}, 30 \mathrm{~s}$ at $72^{\circ} \mathrm{C}$, followed by a final extension for $10 \mathrm{~min}$ at $72^{\circ} \mathrm{C}$. The amplification was performed using a PE2400 thermal cycler (Perkin-Elmer, USA). The PCR fragment was purified using a QIA Quick PCR Purification kit (QIAGEN, USA) according to the manufacturer's protocol. The DNA sequencing was performed using the standard shotgun sequencing reagents and a Genome Sequencer FLX (Roche, USA), according to the manufacturer's instructions by Macrogen Inc. (Korea). Clustering and statistical analysis of sequence data were performed using the Mothur software package (Schloss and Handelsman, 2008). The length of the fragment of the $16 \mathrm{~S}$ rDNA pyrosequenced ranged from 118 to 526 base pairs, with an average length of 472 base pairs. The pyrosequencing data are available in the EMBL SRA 


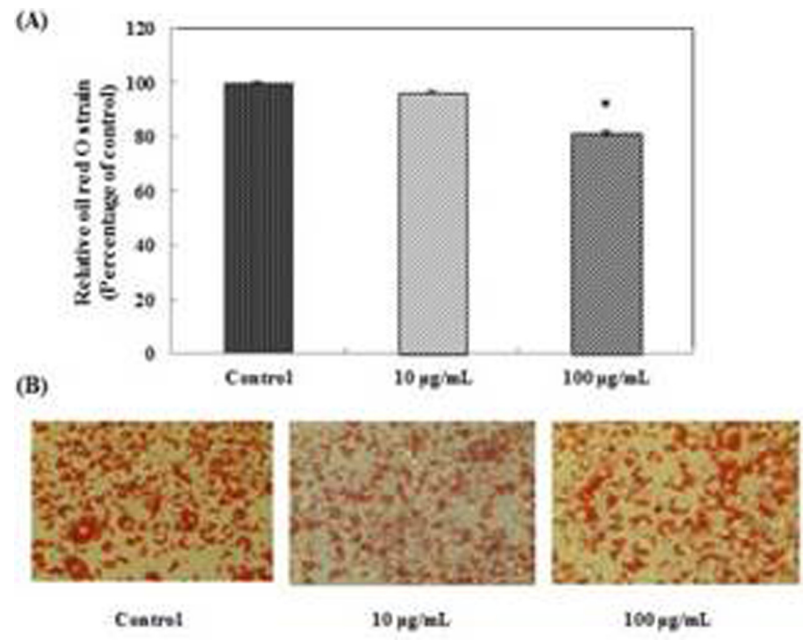

Fig. 1. The effects of Lactobacillus plantarum FH185 on oil red $\mathrm{O}$ stained in 3T3-L1 adipocyte. (A) quantification of oil red $\mathrm{O}$ staining * significant difference from control at $p<0.05$; (B) photograph of oil red $\mathrm{O}$ staining. Cells were stained with oil red $\mathrm{O}$ observed by using a microscope (original magnification $\times 200$ ).

database under the accession number ERP000935.

\section{Measurement of adipocyte size}

The left and right epididymal fat pads were quickly isolated after the animals were sacrificed. Epididymal fat pads were fixed in $10 \%$ formaldehyde solution. According to the method of Hirsch and Gallian (1968), samples were passed through a $250-\mathrm{m}$ nylon filter in order to remove fibrous tissue and intact shreds of fixed adipose tissue. The tissue shreds were flushed thoroughly with PBS. The filtrate was then passed through a 25-m nylon filter to trap fixed adipocytes, and the cells were washed thoroughly with PBS. Cell suspensions were applied to glass slides and then stained with hematoxylin and eosin solutions (H\&E staining), as previously described (van Goor et al., 1986). The cells on the glass slides were observed with a microscope and the adipocyte size were measured using Image J Software (National Institute of Health, USA).

\section{Statistical analysis}

The statistical analysis was performed with a statistical analysis system (SAS, SAS Institute Inc., USA), and the results expressed as the mean \pm standard deviation (SD). The significance of the differences was analyzed by conducting a one-way analysis of variance (ANOVA) with Duncan's multiple range tests. Values of $p<0.05$ were considered statistically significant.
Table 2. Physiological characteristics of Lactobacillus plantarum FH185

\begin{tabular}{|c|c|c|c|}
\hline \multicolumn{2}{|l|}{ Gram reaction } & \multicolumn{2}{|l|}{+} \\
\hline \multicolumn{2}{|l|}{ Cell type } & \multicolumn{2}{|l|}{ rod } \\
\hline \multicolumn{2}{|l|}{ Spore forming } & \multicolumn{2}{|l|}{-} \\
\hline \multicolumn{2}{|l|}{ Motility } & \multicolumn{2}{|l|}{-} \\
\hline \multicolumn{2}{|l|}{ Aerobic growth } & \multicolumn{2}{|l|}{+} \\
\hline \multicolumn{2}{|l|}{ Anaerobic growth } & \multicolumn{2}{|l|}{+} \\
\hline \multicolumn{2}{|l|}{ Catalase reaction } & \multicolumn{2}{|l|}{-} \\
\hline \multicolumn{2}{|l|}{ Growth at 15} & \multicolumn{2}{|l|}{-} \\
\hline \multicolumn{2}{|l|}{ Growth at 45} & \multicolumn{2}{|l|}{-} \\
\hline \multicolumn{2}{|l|}{ Gas forming from glucose } & \multicolumn{2}{|l|}{-} \\
\hline \multicolumn{2}{|l|}{ Ammonia production from alginin } & \multicolumn{2}{|l|}{-} \\
\hline \multicolumn{4}{|l|}{ Acid production from } \\
\hline Glycerol & - & Salicin & + \\
\hline Erythritol & - & D-Celiobiose & + \\
\hline D-Arabinose & - & D-Maltose & + \\
\hline L-Arabinose & + & D-Lactose & + \\
\hline D-Ribose & + & D-Melibiose & + \\
\hline D-Xylose & - & D-Saccharose & + \\
\hline L-Xylose & - & D-Trehalose & + \\
\hline D-Adonitol & - & Inulin & - \\
\hline Methyl- $\beta$-D-Xylopyranoside & - & D-Melezitose & + \\
\hline D-Galactose & + & D-Raffinose & + \\
\hline D-Glucose & + & Amidon(starch) & - \\
\hline D-Fructose & + & Glycogen & - \\
\hline D-Mannose & + & Xylitol & - \\
\hline L-Sorbose & - & Gentiobiose & + \\
\hline L-Rhamnose & - & D-Turanose & + \\
\hline Dulcitol & - & D-Lyxose & - \\
\hline Inositol & - & D-Tagatose & - \\
\hline D-Mannitol & + & D-Fucose & - \\
\hline D-Sorbitol & + & L-Fucose & - \\
\hline Methyl- $\alpha$-D-Mannopyranoside & + & D-Arabitol & - \\
\hline Methyl- $\alpha$-D-Glucopyranoside & - & L-Arabitol & - \\
\hline N-AcetylGlucosamine & + & Potassium Gluconate & + \\
\hline Amygdalin & + & $\begin{array}{c}\text { Potassium } \\
\text { 2-KetoGluconate }\end{array}$ & - \\
\hline Arbutin & + & $\begin{array}{c}\text { Potassium } \\
\text { 5-KetoGluconate }\end{array}$ & - \\
\hline Esculin & + & & \\
\hline
\end{tabular}

\section{Results and Discussion}

\section{Isolation of lactic acid bacteria}

The feces samples were collected from healthy adult staff members of the Korea Food Research Institute (Korea), and 188 strains were isolated as lactic acid bacteria in a modified MRS medium. The strain was incubated in lactobacilli MRS broth as the growth medium at $37^{\circ} \mathrm{C}$ for $18 \mathrm{~h}$.

\section{Selection of strain of anti-obesity activity}

Several approaches to the prevention and treatment of 
obesity have been reported (Birari and Bhutani, 2007). Among these, both natural and synthetic pancreatic lipase inhibitors are effective in preventing obesity, which is considered likely to be due to their inhibition of intestinal lipid absorption (Hirose et al., 2013). After being incubated in MRS broth at $37^{\circ} \mathrm{C}$ for $18 \mathrm{~h}$, three kinds of strains having a lipase inhibitory activity of over $60 \%$ were selected from among the 188 strains by measuring their lipase inhibitory activity. The FH185 strain exhibited a lipase inhibitory activity of $70.09 \pm 2.04 \%$ compared with the control group. Fig. 1 shows that an 8-day treatment at various concentrations $[0-100 \mu \mathrm{g} / \mathrm{mL}]$ of the $\mathrm{FH}$ 185 strain during the differentiation period significantly and dose-dependently inhibited 3T3-L1 adipogenesis in terms of lipid accumulation compared with the control cells. Among the tested concentrations of FH185, $100 \mu \mathrm{g} /$ $\mathrm{mL}$ was the most effective at reducing the lipid content in differentiated cells (by $18.63 \pm 0.98 \%$ compared with the control cells). These results suggest that FH185 inhibits pancreatic lipase (PL) and the differentiation of 3T3-L1 pre-adipocytes by suppressing lipid accumulation.

\section{Identification and DNA sequencing of the selected FH185 strain}

Physiological and biochemical tests were conducted to determine the genus and species of the selected FH185 strain. The FH185 strain consisted of non-spore, rod-type, gram-positive bacteria and exhibited negative properties on catalase and motility. In addition, it cannot grow at $15^{\circ} \mathrm{C}$ or $45^{\circ} \mathrm{C}$. As it does not produce gas and ammonia from glucose and arginine, it has been identified as a genus Lactobacillus (Table 2). After PCR amplification using universal primers targeting $16 \mathrm{~S}$ rDNA and the following sequence analysis, it was identified as L. plantarum with a similarity of $99 \%$ (data not shown). Based on the results of previous studies, it was named L. plantarum FH185 (Fig. 2).

\section{Change of gut microbiota}

The fecal samples collected on the first day of 0 wk and the last day of 6 wk were analyzed for their fecal microbiota. According to the results of fecal pyrosequencing, compared with $6 \mathrm{wk}$, at the phylum level, there was a greater increase in phylum Firmicutes than Bacteroidetes

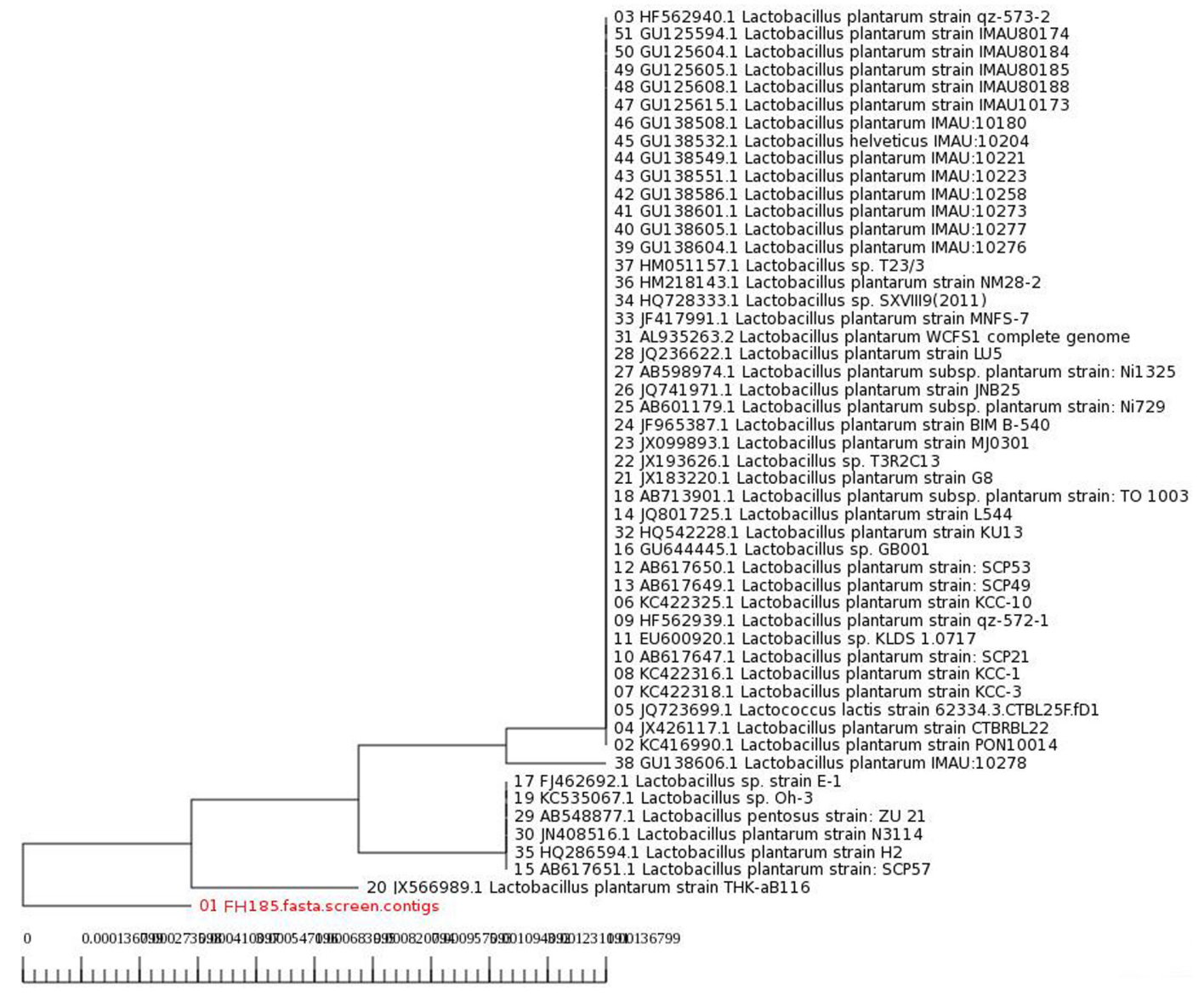

Fig. 2. Phylogenetic tree of Lactobacillus plantarum FH185 isolated from adult feces. 
in group A, which was the control group fed with the ND. Meanwhile, in group B, the control group fed with the HFD, there was a slight increase in Bacteroidetes; whereas in group $\mathrm{C}$, the group fed with the HFD and orally administered with ABT-3, the was a considerable increases in Bacteroidetes. In addition there was an increase in Bacteroidetes in group D, which was fed with the HFD and orally administered with $L$. plantarum FH185. Ley et al. (2006) have demonstrated that $o b / o b$ mice had a reduction in the abundance of Bacteroidetes and a proportional increase in Firmicutes. They also found that obese people had a lower proportion of Bacteroidetes/Firmicutes than lean people. It means that $L$. plantarum $\mathrm{FH} 185$ has an anti-obesity effect (Fig. 3(a) and (b)).

Next, we analyzed the differences in gut microbiota composition at the family level. The Lactobacillaceae family was observed to dominate in all groups before the start of treatment. However, the Lachnospiraceae family was observed to dominate in group A. In group B, Lachnospiraceae was also observed to dominate, but the amount of Porphyromonadaceae increased only slightly. In group C, Lactobacillaceae and Lachnospiraceae were observed to dominate equally. In case of group D, it displayed a similar tendency with group C, but the Lactobacillaceae family was observed to be slightly more prevalent than the Lachnospiraceae family. Also, the amount of Bacteroidaceae and Porphyromonadaceae increased slightly in groups C and D. Lactobacillaceae and Lachnospiraceae were the families of Bacteroidetes, while Bacteroidaceae and Porphyromonadaceae were the families of Firmicutes (Nava et al., 2011) (Fig. 3(c) and (d)).

At the genus level, an unknown spp. was observed to dominate after six weeks, while the Lactobacillus spp. in all groups was observed to dominate before the start of the treatment. However, the Lactobacillus spp. in groups $\mathrm{C}$ and $\mathrm{D}$ was comparatively higher than in groups $\mathrm{A}$ and B (Fig. 3(e) and (f)).

\section{Adipocyte size}

The epididymal fat pads of the mice were quickly isolated and the adipocyte size was observed and measured. In group A, which was the control group fed with the ND, the percentage of $2,000 \mathrm{~m}^{2}$ of adipocyte was higher than in the other size of adipocyte. In groups $\mathrm{C}$ and $\mathrm{D}$, i.e., those fed with the HFD and orally administrated with ABT-3 and L. plantarum FH185, the percentage of 2000 $\mathrm{m}^{2}$ of adipocyte was also higher than in the other size of adipocyte. However, the percentage of over $5000 \mathrm{~m}^{2}$ of adipocyte was highest in group B, the control group fed

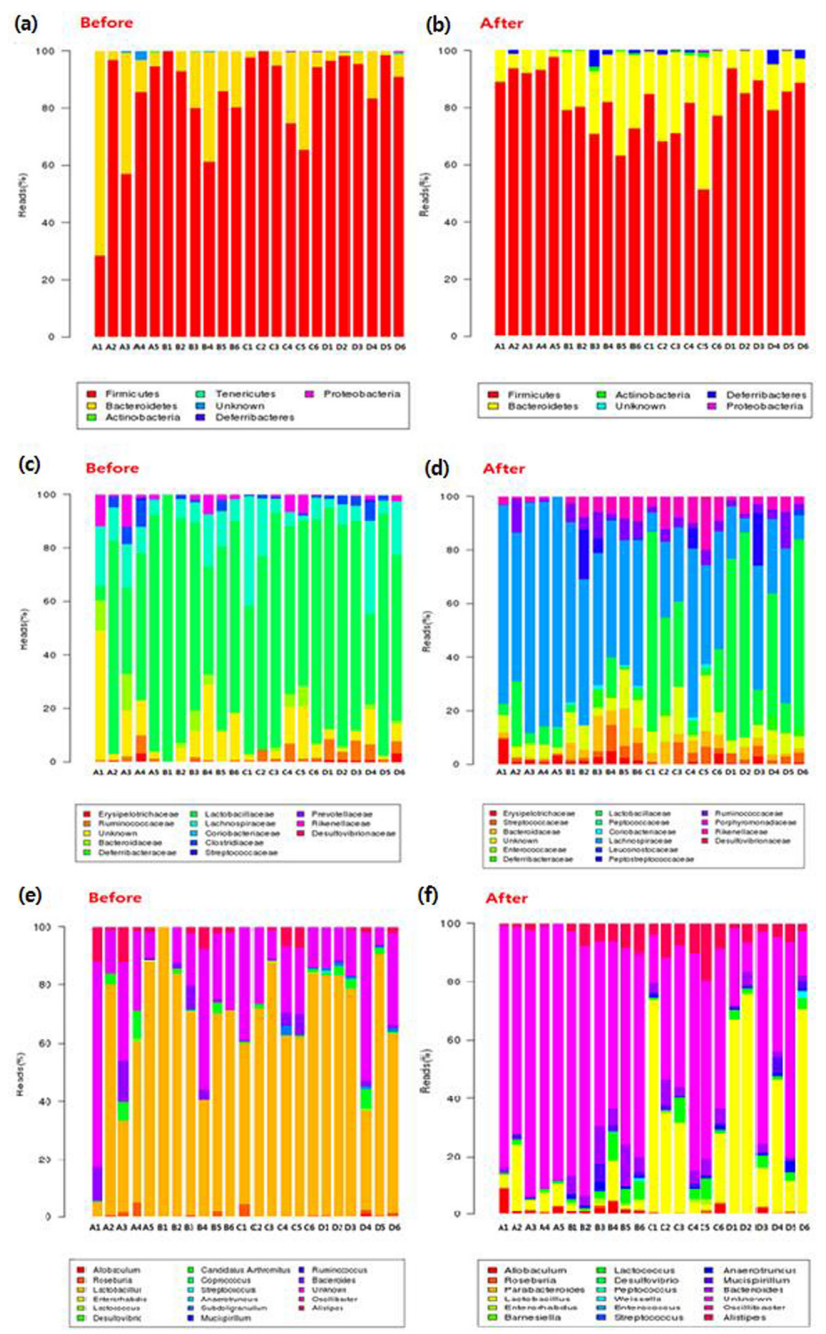

Fig. 3. Proportion or taxonomic assignment at phylum level $(a, b)$, family level $(c, d)$, and genus level $(e, f)$. A, normal diet; B, high fat diet; C, high fat diet with ABT-3 $\left(10^{9}\right.$ CFU/d); D, high fat diet with $L$. plantarum FH185 $\left(10^{9}\right.$ $\mathrm{CFU} / \mathrm{d})$.

with the HFD. In addition, the average adipocyte size of group B was found to be higher than that of the other groups (Fig. 4). Indeed, Cani et al. (2007) previously reported that a high-fat diet increased the size of adipocyte cells. Moreover, in their after-study (Cani et al. 2008), the mean adipocyte size was reduced in high-fat antibiotic treated mice when compared with high-fat untreated mice. They concluded that the antibiotic treatment was associated with changes in the size of adipocyte cells. Thus, the results suggest that $L$. plantarum $\mathrm{FH} 185$ has an effect on reduction of adipocyte size.

\section{Conclusion}

This study aimed to investigate the effects of $L$. plan- 

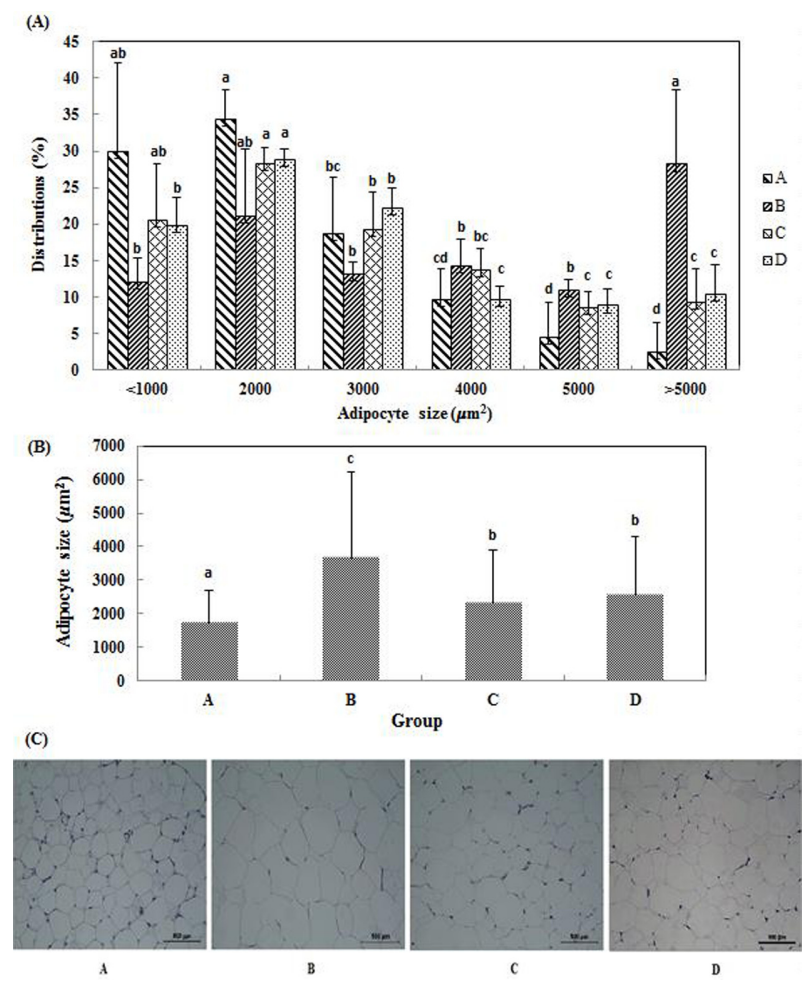

Fig. 4. Changes in adipocyte size of the epididymal fat pads in mouse. Values are mean $\pm \mathrm{SD}$ of 6 mice per group; (A) Percentage of cell number; ${ }^{\mathrm{a}-\mathrm{c}}$ Means that the values with different superscripts within the same group are significantly different $(p<0.05)$. (B) The adipocyte size, ${ }^{\mathrm{a}-\mathrm{c}}$ Means that the values with different superscripts are significantly different $(p<0.05)$. (c) Photograph of the epididymal fat pads in mouse (original magnification $\times 200$ ). A, normal diet; B, high fat diet; $\mathrm{C}$, high fat diet with ABT-3 $\left(10^{9}\right.$ CFU/d); D, high fat diet with $L$. plantarum FH185 $\left(10^{9}\right.$ CFU/d).

tarum $\mathrm{FH} 185$ isolated from human feces on the reduction of adipocyte size and gut microbial changes in mice with diet-induced obesity. The strain was found to have a lipase inhibitory activity of $70.09 \pm 2.04 \%$ and to inhibit the adipocyte differentiation of 3T3-L1 cells (18.63 $\pm 0.98 \%)$ at a concentration of $100 \mu \mathrm{g} / \mathrm{mL}$. The gut microbial changes in mice with diet-induced obesity were investigated. Male $\mathrm{C} 57 \mathrm{BL} / 6 \mathrm{~J}$ mice were fed on different diets (A, normal diet (ND); B, high-fat diet (HFD); C, HFD with ABT-3 $\left(10^{9} \mathrm{CFU} /\right.$ day $)$; and D, HFD with L. plantarum $\mathrm{H}-$ $185\left(10^{9} \mathrm{CFU} /\right.$ day $\left.)\right)$ for $6 \mathrm{wk}$. According to the results of fecal pyrosequencing, the ratio of Firmicutes to Bacteroidetes in groups $\mathrm{C}$ and $\mathrm{D}$ was lower than of the control groups at the phylum level. At the family level, the Lactobacillaceae family was observed to dominate in groups $\mathrm{C}$ and $\mathrm{D}$, while Lachnospiraceae was observed to dominate in groups A and B. At the genus level, an unknown spp. was observed to dominate after six weeks, while the Lactobacillus spp. in all groups was observed to dominate before the start of the treatment. However, the Lactobacillus spp. in groups $\mathrm{C}$ and $\mathrm{D}$ was comparatively higher than in groups $\mathrm{A}$ and $\mathrm{B}$. In groups $\mathrm{A}, \mathrm{C}$ and $\mathrm{D}$, the percentage of $2,000 \mathrm{~m}^{2}$ of adipocyte was higher than in the other size of adipocyte, while the percentage of over 5,000 $\mathrm{m}^{2}$ of adipocyte was highest in group B. The mean adipocyte size of group D was significantly larger than that of group A, but smaller than that of group B.

According to the results, L. plantarum FH185 has potential as a probiotic with anti-obesity effects.

\section{Acknowledgements}

This study was supported by a grant from the Korea Food Research Institute (project no. E0143023839).

\section{References}

1. An, M. A., Park, S. Y., Lee, D. K., Kim, J. R., Cha, M. K., Lee, S. W., Lim, H. T., Kim, K. J., and Nam, J. H. (2011) Antiobesity and lipid-lowering effects of Bifidobacterium spp. in high fat diet induced obese rats. Lipids Health Dis. 10, 116-123.

2. Arora, T., Anastasovska, J., Gibson, G., Tuohy, K., Sharma, R. K., Bell, J., and Frost, G. (2012) Effect of Lactobacillus acidophilus NCDC 13 supplementation on the progression of obesity in diet-induced obese mice. Br. J. Nutr. 108, 9-1382.

3. Bhathena, J., Martoni, C. Kulamarva, A., Urbanska, A. M., Malhotra, M., and Prakash, S. (2009) Orally delivered micro encapsulated live probiotic formulation lowers serum lipids in hypercholesterolemic hamsters. J. Med. Food 12, 310-319.

4. Birari, R. B. and Bhutani, K. K. (2007) Pancreatic lipase inhibitors from natural sources: Unexplored potential. Drug. Discov. Today 12, 879-889.

5. Cani, P. D., Amar, J., Iglesias, M. A., Poggi, M., Knauf, C., Bastelica, D., Neyrinck, A. M., Fava, F., Tuohy, K. M., Chabo, C., Waget, A., Delmee, E., Cousin, B., Sulpice, T., Chamontin, B., Ferrieres, J., Tanti, J. F., Gibson, G. R., Casteilla, L., Delzenne, N. M., Alessi, M. C., and Burcelin, R. (2007) Metabolic endotoxemia initiates obesity and insulin resistance. Diabetes 56, 1761-1772.

6. Cani, P. D., Bibiloni, R., Knauf, C., Neyrinck, A. M., and Delzenne, N. M. (2008) Changes in gut microbiota control metabolic diet-induced obesity and diabetes in mice. Diabetes 57, 1470-1481.

7. Delzenne, N. M., Neyrinck, A. M., Bäckhed, F., and Cani, P. D. (2011) Targeting gut microbiota in ocesity: Effects of prebiotics and probiotics. Nat. Rev. Endocrinol. 7, 639-646.

8. FAO and WHO (2001) Health and nutritional properties of probiotic in food including powder milk with live lactic acid bacteria. Report of joint FAO/WHO expert consultation on evaluation of health and nutritional properties of probiotics 
in food including powder milk with live lactic acid bacteria. Cordoba, Argentina, October 1-4, pp. 19-20.

9. Guandalini, S. (2008) Probiotics for children with diarrhea: an update. J. Clin. Gastroenterol. 42, S53-S57.

10. Haslam D. W. and James W. P. (2005) Obesity. Lancet. 366, 1197-1209.

11. Hemati, N., Ross, S. E., Erickson, R. L, Groblewski, G. E., and MacDuygald, O. A. (1997) Signaling pathways through which insulin regulates CCAAT/enhancer binding protein- $\alpha$ $(\mathrm{C} / \mathrm{EBP}-\alpha)$ phosphorylation and gene expression in 3T3-L1 adipocytes. Forrelation with CLUT4 gene expression. J. Biol. Chem. 272, 25913-25919.

12. Hirose, M., Ando, T., Shofiqur, R., Umeda, K., Kodama, Y., Nguyen, S. V., Goto, T., Shimada, M., and Nagaoka, S. (2013) Anti-obesity activity of hen egg anti-lipase immunoglobulin yolk, a novel pancreatic lipase inhibitor. Nutr. Metab. 10, 7076.

13. Hirsch, J. and Gallian, E. (1968) Methods for the determination of adipose cell size in man and animals. J. Lipid Res. 9, 110-119.

14. Isolauri, E. and Salminen, S. (2008) Probiotics: Use in allergic disorders: A Nutrition, Allergy, Mucosal Immunology, and Intestinal Microbiota (NAMI) research group report. J. Clin. Gastroenterol. 42, S91-S96.

15. Iwashita, S., Tanida, M., Terui, N., Ootsuka, Y., Shu, M., Kang, D., and Suzuki, M. (2002) Direct measurement of renal sympathetic nervous activity in high-fat diet-related hypertensive rats. Life Sci. 71, 46-537.

16. Kumar, M., Kumar, A., Nagpal, R., Mohania, E., Behare, P., Verma, V., Kumar, P., Poddar, D., Aggarwal, P. K., Henry, C. J., Jain, S., and Yadav, H. (2010) Cancer-preventing attributes of probiotics: an update. Int. J. Food Sci. Nutr. 61, 473-496.

17. Lay, C., Sutren, M., Rochet, V., Saunier, K., Doré, J., and Rigottier-Gois, L. (2005) Design and validation of 16S rDNA probes to enumerate members of the Clostridium leptum subgroup in human faecal microbiota. Environ. Microbiol. 7, 933-946.

18. Lee, K., Paek, K., Lee, H. Y., Park, J. H., and Lee, Y. (2007) Anti obesity effect of trans-10, cis-12 conjugated linoleic acidproducing Lactobacillus plantarum PL62 on diet-induced obese mice. J. Appl. Microbiol. 103, 1140-1146.

19. Lee, Y. P., Chung G. H., and Rhee, J. S. (1993) Purification and characterization of Pseudomonas fluorescens SIK W1 lipase expressed in Escherichia coli. Biochim. Biophys. Acta. 1169, 156-164.

20. Ley, R. E., Turnbaugh, P., Klein, S., and Gordon, J. I. (2006) Microbial ecology human gut microbes associated with obe- sity. Nature 444, 1022-1023.

21. Lim, S. D., Kim, K. S., and Do, J. R. (2011) Physiological characteristics and production of vitamin $\mathrm{K}_{2}$ by Lactobacillus fermentum LC272 isolated from raw milk. Korean J. Food Sci. Ani. Resour. 31, 513-520.

22. Liu, W. T., Marsh, T. L., Cheng, H., and Forney, L. J. (1997) Characterization of microbial diversity by determining terminal restriction fragment length polymorphisms of genes encoding 16S rRNA. Appl. Environ. Microbiol. 63, 4516-4522.

23. Mennigen, R. and Bruewer, M. (2009) Effect of probiotics on intestinal barrier function. Ann. NY. Acad. Sci. 1165, 183189.

24. Nava, G. M., Friedrichsen, H. J., and Stappenbeck, T. S. (2011) Spatial organization of intestinal microbiota in the mouse ascending colon. ISME J. 5, 627-638.

25. Nguyen, T. D., Kang, J. H., and Lee, M. S. (2007) Characterization of Lactobacillus plantarum $\mathrm{PH} 04$, a potential probiotic bacterium with cholesterol-lowering effects. Int. J. Food Microbiol. 113, 358-361.

26. Perdigón, G., Fuller, R., and Raya, R. (2001) Lactic acid bacteria and their effect on the immune system. Curr. Issues Intest. Microbiol. 2, 27-42.

27. Ramirez-Zacarias, J. L., Castro-Munozledo, F., and Kuri-Harcuch, W. (1992) Quantitation of adipose conversion and triglycerides by staining intracytoplasmic lipids with Oil red O. Histochem. 97, 493-497.

28. Rogosa, M. (1974) Genus I. Lactobacillus. In: Bergey's manual of determinative bacteriology. 8th ed. Buchanan, R. E. and Gibbons, N. E. (eds), Williams and Wilkins Co., Baltimore, pp. 576-593.

29. Schloss, P. D. and Handelsman, J. (2008) A statistical toolbox for metagenomics: assessing functional diversity in microbial communities. BMC Bioinformatics 9, 34 .

30. Stein, C. J. and Colditz, G. A. (2004) The epidemic of obesity. J. Clin. Endocrinol. Metab. 89, 2522-2525.

31. Tanida, M., Shen, J., Maeda, K., Horii, Y., Yamano, T., Fukushima, Y., and Nagai, K. (2008) High-fat diet-induced obesity is attenuated by probiotic strain Lactobacillus paracasei ST11 (NCC2461) in rats. Obes. Res. Clin. Pract. 2, 1-11.

32. Turnbaugh, P. J., Hamady, M., Yatsunenko, T., Cantarel, B. L., Duncan, A., Ley, R. E., Sogin, M. L., Jones, W. J., Roe, B. A., Affourtit, J. P., Egholm, M., Henrissat, B., Heath, A. C., Knight, R., and Gordon, J. I. (2009) A core gut microbiome in obese and lean twins. Nature 457, 480-484.

33. van Goor, H., Gerrits, P. O., and Grond, J. (1986) The application of lipid-soluble stains in plastic-embedded sections. Histochemistry 85, 251-253. 